\title{
Profiling of relaxin and its receptor proteins in boar reproductive tissues and spermatozoa
}

Jean M Feugang ${ }^{1 *}$, Jonathan M Greene ${ }^{1,2,5}$, Hector L Sanchez-Rodríguez ${ }^{1,6}$, John V Stokes ${ }^{3}$, Mark A Crenshaw ${ }^{1}$, Scott T Willard ${ }^{1,4}$ and Peter L Ryan ${ }^{1,2}$

\begin{abstract}
Background: Relaxin levels in seminal plasma have been associated with positive effects on sperm motility and quality, and thus having potential roles in male fertility. However, the origin of seminal relaxin, within the male reproductive tract, and the moment of its release in the vicinity of spermatozoa remain unclear. Here, we assessed the longitudinal distribution of relaxin and its receptors RXFP1 and RXFP2 in the reproductive tract, sex accessory glands, and spermatozoa of adult boars.
\end{abstract}

Methods: Spermatozoa were harvested from three fertile boars and reproductive tract (testes and epididymis) and sex accessory gland (prostate and seminal vesicles) tissues were collected post-mortem from each boar. Epididymis ducts were sectioned into caput, corpus, and cauda regions, and spermatozoa were mechanically collected. All samples were subjected to immunofluorescence and/or western immunoblotting for relaxin, RXFP1, and RXFP2 detection. Immunolabeled-spermatozoa were submitted to flow cytometry analyses and data were statistically analyzed with ANOVA.

Results: Both receptors were detected in all tissues, with a predominance of mature and immature isoforms of RXFP1 and RXFP2, respectively. Relaxin signals were found in the testes, with Leydig cells displaying the highest intensity compared to other testicular cells. The testicular immunofluorescence intensity of relaxin was greater than that of other tissues. Epithelial basal cells exhibited the highest relaxin immunofluorescence intensity within the epididymis and the vas deferens. The luminal immunoreactivity to relaxin was detected in the seminiferous tubule, epididymis, and vas deferens ducts. Epididymal and ejaculated spermatozoa were immunopositive to relaxin, RXFP1, and RXFP2, and epididymal corpus-derived spermatozoa had the highest immunoreactivities across epididymal sections. Both vas deferens-collected and ejaculated spermatozoa displayed comparable, but lowest immunofluorescence signals among groups. The entire sperm length was immunopositive to both relaxin and receptors, with relaxin signal being robust in the acrosome area and RXFP2, homogeneously distributed than RXFP1 on the head of ejaculated spermatozoa.

Conclusions: Immunolocalization indicates that relaxin-receptor complexes may have important roles in boar reproduction and that spermatozoa are already exposed to relaxin upon their production. The findings suggest autocrine and/or paracrine actions of relaxin on spermatozoa, either before or after ejaculation, which have possible roles on the fertilizing potential of spermatozoa.

Keywords: Fertility, Immunofluorescence, Leydig cells, Pig, Relaxin, Semen, Seminal plasma, Sertoli cells, Sperm motility

\footnotetext{
* Correspondence: jn181@ads.msstate.edu

'Department of Animal and Dairy Sciences, Facility for Organismal and Cellular Imaging (FOCI), Mississippi State University, Mississippi State, MS 39762, USA

Full list of author information is available at the end of the article
} 


\section{Background}

Sertoli cells build tight junctions among themselves in the testes to form a blood-testis barrier that maintains an enclosed microenvironment favoring normal sperm production. Upon their release within the seminiferous tubule lumen, newly produced spermatozoa are exposed to various molecules that contribute to the acquisition of their final maturation during the epididymal transit $[1,2]$. The epididymis is a long duct consisting of various sections with specific functions, known to secrete and reabsorb a variety of molecules that locally interact with spermatozoa to influence their fertilizing potential [3-6]. Relaxin might be one of these molecules, whose presence in the seminal plasma contributes to the crucial roles of this fluid in mammalian fertilization through beneficial effects on sperm motility [7-10].

Relaxin peptide was discovered in the early part of the twentieth century and is characterized as hormone of pregnancy because of its roles during parturition [11]. The first report on relaxin used pregnant guinea pig serum relaxin to demonstrate its beneficial effect on widening the birth canal of non-pregnant animals [12]. Further works later confirmed its positive effects during pregnancy and parturition in various species such as monkeys, pigs, and rodents [13-15]. At present, numerous studies have detected the presence of relaxin in both female (i.e., uterus, ovary) and male (i.e., testes, seminal vesicles, prostate) reproductive tissues, and its functions have been reported in various reproductive and non-reproductive (i.e., brain, pancreas, and kidney) tissues [11].

The tissular distribution of relaxin varies across species and its pleiotropic biological effects are exerted through membrane receptors, known as relaxin family peptide receptor 1 (RXFP1) and 2 (RXFP2) and corresponding to the former leucine-rich repeat-containing G-protein-coupled receptor 7 (LGR7) and 8 (LGR8), respectively [16]. The cellular and physiological effects of relaxin-receptor interactions are better characterized in females, mainly during early and late pregnancy $[13,17$, $14,18]$, and the co-localization of both relaxin and its receptors in various tissues (i.e., oocytes, cervix, uterus, mammary gland) indicate the existence of possible autocrine and paracrine actions of relaxin [19, 20, 11, 21]. Yet, the presence of both relaxin receptors mRNA and proteins in male reproductive organs is still controversial among studies and species, and consequently, little remains known about relaxin's presence and roles in male reproductive organs; especially its contribution to the fertilizing potential of spermatozoa [21].

Relaxin is found in male reproductive tissues and accessory glands of various species, and its main production sites appear species-specific [21, 11], with testes, seminal vesicles, and prostate being reported as the major sources of production in various species [21, 22].
Although there are still controversies about the major site of relaxin production in boars [23, 24, 22, 25, 26], a recent study tends to support the testes as the major site of relaxin production, as both RNA transcript and protein were detected in Leydig cells during porcine postnatal development [24]. Nonetheless, the potential roles of testicular relaxin in male reproduction are still controversial, despite various knock-out studies conducted in rodents [21, 27].

Available data in the literature body imply that spermatozoa may be exposed to relaxin within the reproductive tract. The confirmation of this assumption in pigs will contribute to understanding the physiological effects of testicular relaxin on male fertility, as its levels in semen ejaculates appear correlated to sperm motility [8]. Additionally, in vitro studies revealed positive effects of relaxin usually extracted from female tissues (e.g., ovary) on postmating events such as, cervical mucus penetration [28], acrosome reaction, mitochondrial potential, hyperactivation of spermatozoa [29, 30], and oocyte maturation [31]. Hence, it becomes reasonable to question whether it is the male- and/or the female-produced relaxin that provide such effects in the physiological conditions.

From the available literature, it appears that the dynamic expression of relaxin and its receptors throughout the boar reproductive tract, which will provide additional insights into the reproductive impacts of relaxin on male fertility, have not been the focus of previous studies. The current study was undertaken to investigate the main source (s) of relaxin accumulation and the presence of its receptors RXFP1 and RXFP2 in boar reproductive tract (testis, epididymis, and vas deferens) and sex accessory glands (prostate and seminal vesicles). In addition, we profiled the presence of both relaxin and receptor proteins in porcine epididymal and ejaculated spermatozoa. The major findings are that: 1) relaxin and its receptors are present in both reproductive tract and accessory glands, 2) relaxin mainly accumulates within the Leydig cells of the testis, and lower levels were detected in the prostate and seminal vesicles, 3) relaxin is found within the lumen and epithelia of seminiferous tubules and epididymis, in the vicinity of produced and maturing spermatozoa, 4) spermatozoa possess both relaxin and receptor proteins with the amount varying significantly during the epididymal transit, and 5) ejaculated spermatozoa contain both relaxin and receptors RXFP1 and RXFP2 that likely support the longterm roles of male-born relaxin within the female genital tract, through possible autocrine and/or paracrine action.

\section{Methods}

\section{Chemicals and media}

Unless otherwise indicated, all chemicals and reagents were purchased from Sigma-Aldrich (Saint Louis, MI) for 
general purpose and from Santa Cruz Biotechnologies, Inc. (Santa Cruz, CA) for antibodies.

\section{Sample preparation}

\section{Animals and fresh semen collection}

Three fertile cross-breed boars of approximately $2.7 \pm$ 0.06 (mean \pm sem) years old were used in this study. Fresh semen from each boar was harvested using standard protocol by technicians of a commercial boar stud (Prestage Farms, West Point, MS) and diluted in the Beltsville Thawing Solution (BTS; Minitube of America, Verona, WI). Semen doses were prepared and shipped to our laboratory for experiments. Approximately four hours post-semen collection, all three boars were killed at a local abattoir and reproductive tracts and sex accessory glands (prostate and seminal vesicles) were collected and immediately transported on ice to our laboratory for tissue collections. Ovarian corpus lutea were collected from post-mortem sows at the abattoir for validation studies.

\section{Tissue and spermatozoa collections}

Reproductive tracts of all boars $(n=3)$ were dissected into testes, epididymis (caput or head, corpus or body, and cauda or tail), vas deferens, and accessory glands (prostate and seminal vesicles). All tissue samples were recovered and kept on ice. Spermatozoa within each section of the epididymis and vas deferens were mechanically collected (by aspiration with syringes, flushing with a pre-warmed PBS-PVP, and squeezing) and transferred into petri-dishes containing pre-warmed PBS-PVP. Ejaculated and non-ejaculated spermatozoa collected above were subjected to a purification procedure using a single layer percoll gradient (PorciPure, Nidacon: Mölndal, Sweden), as previously described [32]. After centrifugation (600 g - 30 minutes), pelleted spermatozoa devoid of any contaminations (cell debris, extender components, and somatic cells), were washed twice with a cold PBS-PVP through centrifugation (250 g -5 minutes each). Purified spermatozoa were aliquoted and stored at $-20{ }^{\circ} \mathrm{C}$ until use for protein analyses. In parallel, subsets of dissected tissues (testis, epididymal caput, corpus and cauda, vas deferens, prostate, and seminal vesicles) were stored at room temperature in containers filled with $10 \%$ formalin for immunofluorescence, while the other subsets were wrapped in aluminum foils, snapfrozen, and stored at $-20^{\circ} \mathrm{C}$ for protein analyses.

\section{Western immunoblotting}

All samples were thawed at room temperature and total proteins were extracted using complete RIPA buffer containing a protease inhibitor cocktail (Santa Cruz Biotechnologies; Santa Cruz, CA). Total extracted protein were quantified using the Pierce BCA kit (Thermo Fisher Scientific; Rockford, IL) and equivalents of $20 \mu \mathrm{g}$ were resolved onto 4-12.5 \% SDS-PAGE NuPage gels and transferred to PVDF membranes (Millipore Corp, Belford, USA). Similar amounts of ovarian corpus luteum protein extracts were also loaded into the gels for analyses. All membranes were incubated with $500 \times$ diluted antihuman relaxin (sc-20652), RXFP1 (sc-50328), or RXFP2 (sc-50327) antibodies, which immunogenicities with pig tissues were previously tested [19]. The immunodetection of proteins was revealed by using the Novex ${ }^{\circ}$ HRP Chromogenic Western Blot Immunodetection kit (Life Technologies; Grand Island, NY). In parallel, gel electrophoreses loaded with more protein samples $(40-60 \mu \mathrm{g} /$ well) were ran together with the MagicMark ${ }^{\mathrm{nt}} \mathrm{XP}$ Western Protein Standard (Life Technologies; $10 \mu \mathrm{l} /$ well) for a longer resolution to better determine the protein sizes after immunoblotting.

\section{Protein immunofluorescence detection In spermatozoa}

Purified sperm samples were fixed in $4 \%$ methanol-free paraformaldehyde (30-60 minutes), permeabilized (30 min) in $1 \%$ Triton- $\times 100$, and non-specific binding sites were blocked (60 min) in PBS-PVP solution containing 5 \% BSA (v/v). Sperm suspensions were incubated overnight $\left(4{ }^{\circ} \mathrm{C}\right)$ with 100× diluted rabbit anti-human relaxin 1 (sc-20652), RXFP1 (sc-50328), and RXFP2 (sc-50327) in the blocking buffer. Then after, spermatozoa were incubated one hour with 200x diluted FITC labeled goat anti-rabbit secondary antibody in the blocking buffer. Subsets of labeledspermatozoa were kept in suspensions for a flow cytometry evaluation, while the other subsets were smeared on microscope slides and air-dried under dark. Slides were immediately covered with a DAPI-contained mounting medium to counterstain sperm nuclei for a fluorescence evaluation using a confocal microscope (LSM-510). Samples were washed three times by centrifugation (250 gx 5 min) with PBS-PVP-0.1\% Tween 20 between steps and all procedures were performed at room temperatures otherwise indicated. Samples without any or either primary or secondary antibodies were used as negative controls.

\section{In tissues}

Tissues were fixed in $10 \%$ formalin at room temperature (30-60 minutes) and blocks were sliced in sections $(4-6 \mu \mathrm{m})$ and placed on histological slides. Tissue sections were deparafinized, submitted to antigen retrieval (microwave), washed with PBS-PVP and submitted to immediate standard in situ immunofluorescence detection of relaxin, RXFP1, and RXFP2 proteins. Additionally, pig ovary sections were processed with the anti-synthetic human RXFP1 antibody (AP23448SU-S; ACRIS Antibodies Inc., San Diego, CA) used at 1/4000 
dilution for immunofluorescence signal comparisons with the Santa Cruz anti-human RXFP1.

Reagents used and all procedures were performed as described above for spermatozoa, and samples on the microscope slides were covered with a DAPI-contained mounting medium to counterstain nuclei. The immunofluorescence detection was assessed under a confocal microscope (LSM 510). Samples incubated without primary or secondary antibodies were used as negative controls.

\section{Flow cytometry evaluation}

Suspensions of spermatozoa labeled with relaxin, RXFP1, and RXFP2 antibodies were diluted to approximately $10^{6}$ cells in $0.8 \mathrm{ml}$ PVP-PVP $(1 \mathrm{mg} / \mathrm{ml})$. Samples were analyzed on a Becton Dickinson FACS Aria II flow cytometer (BD Biosciences; San Jose, CA) by excitation with a blue laser $(488 \mathrm{~nm})$. The emission signal was measured in FL2 channel centered at 585/42 nm and sorting was performed with a total of 10,000 events analyzed per sample. Data were acquired with the BD FACSDiva $^{\text {Tw }}$ Version 6.1.3 software and images were treated with the FlowJo software (FlowJo, LLC; Ashland, OR). Three independent experiments were performed and data were expressed as means \pm sem. The mean fluorescence of stained cells with both primary and secondary antibodies minus the mean fluorescence of stained cells with only the secondary antibody was used to calculate the percent of labeled cells.

\section{Confocal microscope imaging}

Immediately after immunolabeling, slides containing specimens (spermatozoa and tissue sections) were submitted to fluorescence signal visualization using a Zeiss Laser Scanning Microscope System (LSM 510; Carl Zeiss MicroImaging $\mathrm{GmbH}$, Jena, Germany) with a $488 \mathrm{~nm}$ excitation. A (DAPI/Fluorescein/Transmission) filter set was used in single channel mode imaging. Excitation

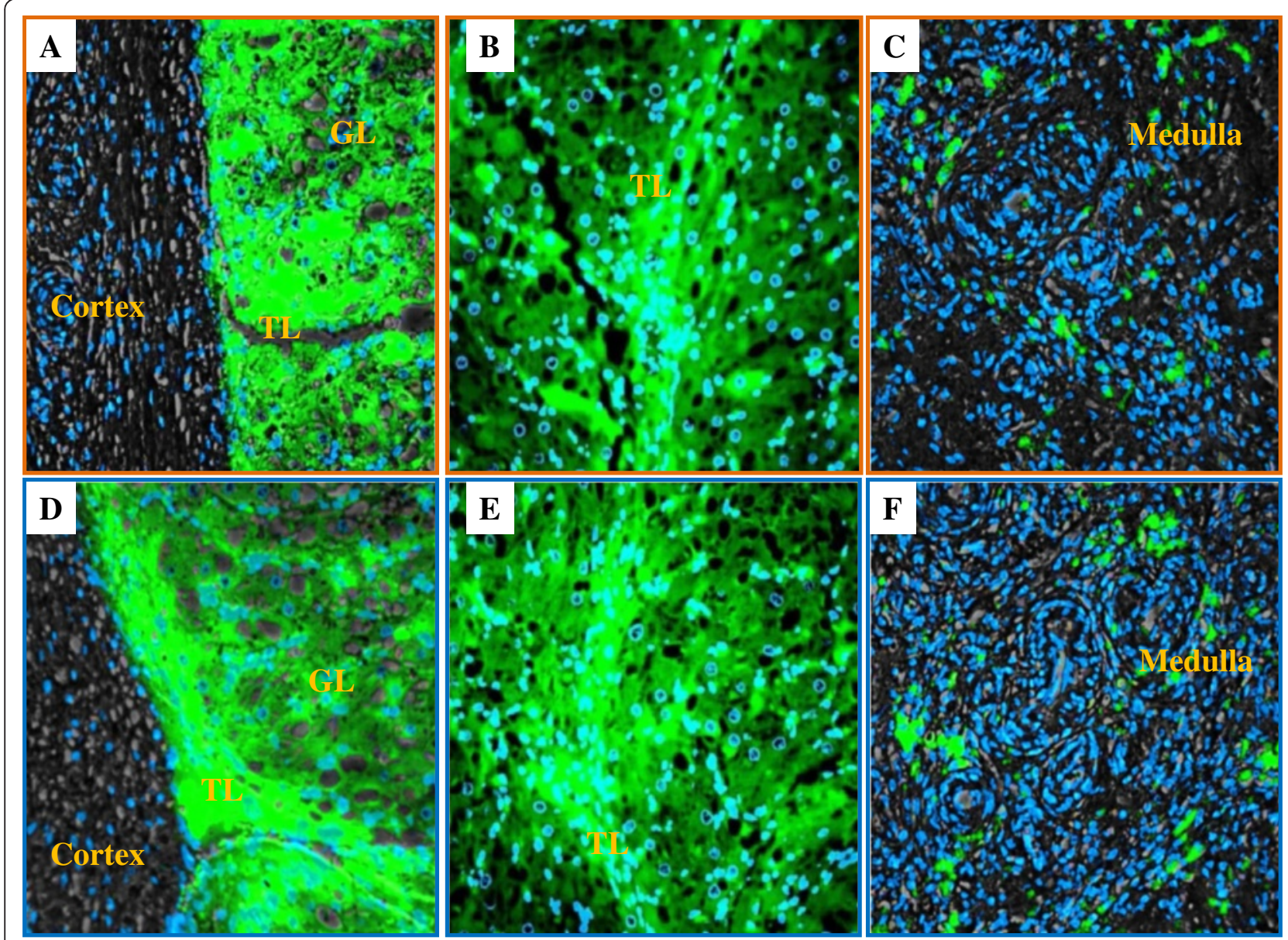

Fig. 1 Validation of specificity and immunogenicity of anti-human relaxin antibody on porcine ovarian tissues. Relaxin is detected (Green-FITC) in sections of superficial ( $\mathbf{a} / \mathbf{d})$ and deep ( $\mathbf{b} / \mathbf{e})$ areas of the corpus luteum, as well as the medulla sections of the sow ovary. Micrographs $\mathbf{a}, \mathbf{b}$ and $\mathbf{c}$ correspond to the labeling with commercial antibody (Santa Cruz Inc., Biotechnology) and micrographs $\mathbf{d}$, $\mathbf{c}$, and $\mathbf{f}$ with the homemade porcine antibody (gift from Dr. Bagnell). $G L=$ Granulosa lutein cells, $T L=$ Theca lutein cells, Magnification $=200 x$. Nuclei are counterstained in blue with DAPI 
wavelengths of $405 \mathrm{~nm} / 488 \mathrm{~nm}$, Band Pass Emission wavelengths of $420-480 \mathrm{~nm}$ (Blue), and Long Pass wavelengths of $505 \mathrm{~nm}$ (Green) were acquired at 1024× 1024 pixel formats for imaging purposes.

\section{Statistical analyses}

Only flow cytometry data were statistically analyzed by ANOVA using the General Linear Model procedures of SPSS, version 22 (IBM statistic package package, version 22, Armonk, NY). The homogeneity of variances was performed using the Levene's test and boars were considered as the random event to evaluate the effect of epididymal section on the immunofluorescence intensity of spermatozoa. The Fisher's Least Square Difference (LSD) test was performed for pairwise comparisons between protein targets (relaxin, RFXP1, or RXFP2), within and between groups (caput, corpus, cauda, and ejaculated sperm). The threshold of statistical significance was fixed at $p \leq 0.05$. Data are mean \pm sem.

\section{Results}

\section{Validation of antibodies}

Ovarian corpus lutea of cyclic sows were used for validation studies due to their known expression of both relaxin and its receptors $[13,11]$. For relaxin detection, we compared the immunofluorescence of a commercial rabbit anti-human relaxin and RXFP1 with a homemade rabbit anti-pig relaxin (gift from Dr. Carol Bagnell at Rutgers University, NJ, USA; Fig. 1) and another commercial source of anti-RXFP1 (ACRIS) reported to be immunoreactive to pig tissues. Antibodies revealed comparable immunolocalization and immunofluorescence intensities in the ovarian corpus luteum and medulla, for anti-relaxin and mural granulosa cells, for anti-RXFP1 (Figs. 1 and 2). Figure 3 shows immunofluorescence detection of relaxin, RXFP1, and RXFP2 in pig samples using commercial antibodies. Weaker or no FITC fluorescence signals were observed in the negative controls, constituted of fixed spermatozoa (micrographs A, B, and C) and sow ovary sections (E). However, the presence of

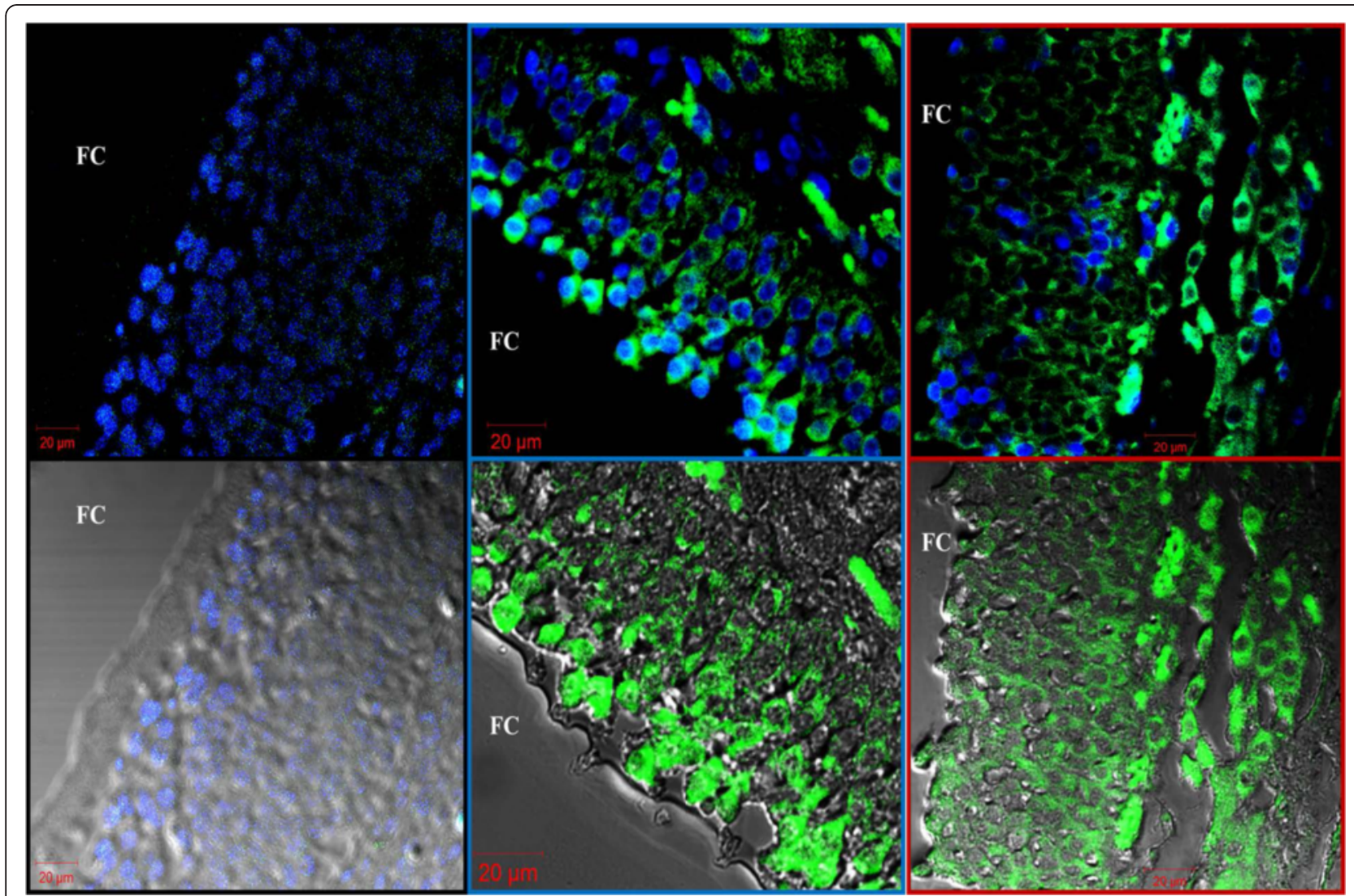

Fig. 2 Immuno-fluorescence comparison of two commercial anti-human RXFP1 antibodies on porcine ovarian tissues. Micrograph show control (no primary antibody; black frame), ACRIS (blue frame), and Santa Cruz (red frame) antibodies. Relaxin receptor RXFP1 is generally stained in Green-FITC and mostly seen in the superficial or plasma membrane regions of (mural granulosa) cells lining the internal follicle wall. Upper panel micrographs indicate cells counterstained with DAPI for the nuclei visualization, while the lower panel indicate overlays imaging with visible and fluorescence lights. $\mathrm{FC}=$ follicular cavity or antrum 

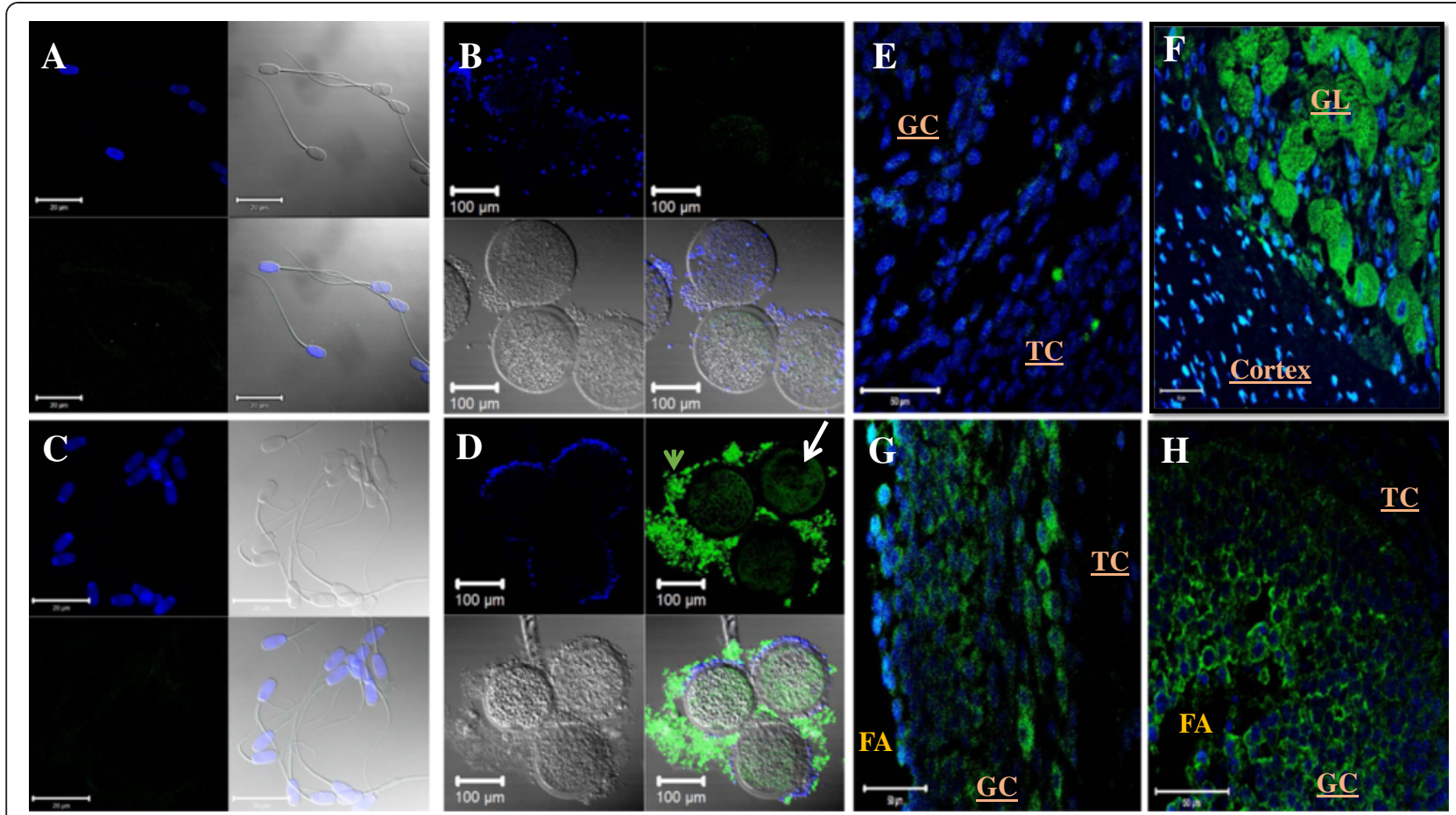

Fig. 3 Immunofluorescence of control samples for relaxin, RXFP1, and RXFP2 detection. Images correspond to negative controls, without the primary antibody in sperm (a), cumulus-oocyte complex (b) and ovary section (e) preparations. Absence or weaker green FITC fluorescence signals were observed following sample incubations with FITC-conjugated antibody only. An illustration is shown in micrograph c. Cumulus-oocyte complexes incubated with anti-relaxin are shown in micrograph $\mathbf{d}$. Micrographs $\mathbf{f}, \mathbf{g}$, and $\mathbf{h}$ are ovary sections incubated with anti-relaxin, anti-RXFP1, and anti-RXFP2 antibodies, respectively. Cells nuclei are counterstained in blue with DAPI, while protein of interests appeared green (FITC). Micrographs $\mathbf{a}, \mathbf{b}, \mathbf{c}$, and $\mathbf{d}$ show stained nuclei, bright-light, green FITC-fluorescence, and the combination of all. Arrow head and arrow respectively indicate the cumulus cells and the oocyte. GC = Granulosa cells; GL = Granulosa Lutein cells; TC = Theca cells; FA = follicle antrum

relaxin was detected in granulosa lutein cells of the corpus luteum (micrograph F) and cumulus cells, a part of the mural granulosa cells layer that surrounding the oocyte (micrograph). The presence of RXFP1 and RXFP2 was also detected in the mural granulosa cells (micrographs $\mathrm{G}$ and $\mathrm{H}$, respectively). Furthermore, the validation of anti-human RXFP1 and RXFP2 after longer electrophoresis and use of appropriate protein marker standard (MagicMark ${ }^{\mathrm{Tm}} \mathrm{XP}$ ) allowed the confirmation of the reported sizes of RXFP1 ( 82 and $67 \mathrm{kDa}$ isoforms) and RXFP2 ( 90 and $78 \mathrm{kDa}$ isoforms) (Fig. 4). Both receptor sizes remained unchanged between all samples (corpus luteum or CL. Testes or TE, ejaculated spermatozoa at high - SP-1 - or low - SP-2 - concentrations) and displayed similar band sizes, while the RXFP2 band appeared lower than RXFP1 in spermatozoa (Fig. 4).

\section{Western immunoblotting}

All tissue samples (testes, prostate, seminal vesicles, vas deferens, and epididymal caput, corpus and cauda) revealed band sizes that were comparable to those detected in the corpus luteum, and corresponding to RXFP 1 and RXFP 2 receptors (Fig. 4). An additional protein band of approximately $32 \mathrm{kDa}$ was detected with the anti-RXFP2 antibody in male tissues exclusively. The bands of $82 \mathrm{kDa}$ (for RXFP 1) and 78 and $32 \mathrm{kDa}$ (for RXFP2) were strongly detected across tissue samples.

\section{Tissular immunofluorescence detection of relaxin}

Higher relaxin detection signal was found in the testis tissue compared to the prostate and seminal vesicle tissues (Fig. 5A, B, \& C). The testicular signal was mainly seen in the interstitium (Leydig cells) and additional immunoreactivities were found in the lumen of seminiferous tubules, spermatids (Fig. 5A-1 \& A-2), Sertoli cells, and spermatocytes (Fig. 5A-3). In the epididymis, relaxin signals were pronounced in epithelial principal and epithelial basal cells (Fig. 6A-D). In the middle section of the vas deferens, the smooth circular muscle (SCM) layer showed immunopositive reactivity to relaxin, while the longitudinal (SLM) layer appeared immunonegative (Fig. 6E/F). Figure 6 (A to F) shows relaxin immunoreactivity throughout the epididymis and vas deferens lumen, in the vicinity of the luminal spermatozoa. Finally, the lumen of blood vessels within the reproductive tract and 


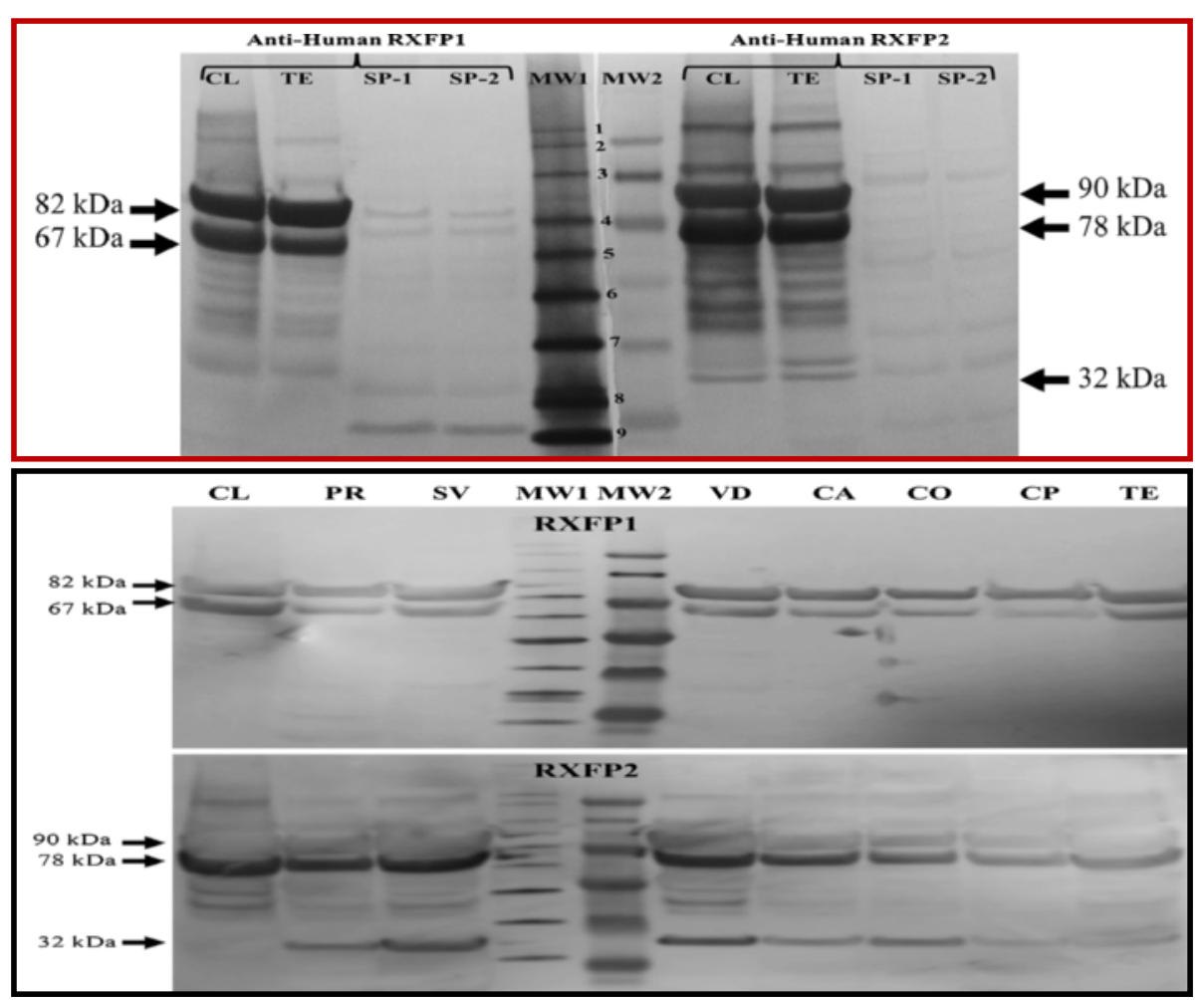

Fig. 4 Representative RXFP1 and RXFP2 western immunoblotting gels. Equal amounts (20-60 $\mu$ g) of total proteins obtained from various pig tissues were resolved on 4-12.5\% SDS-PAGE gels, transferred to PVDF membranes, and immunoblotted with commercial anti-RXFP1 (sc-50328) and anti-RXFP2 (sc-50327) antibodies. Proteins were extracted from prostate (PR), seminal vesicles (SV), vas deferens (VD), and epididymis sections of cauda (CA), corpus (CO), caput (CP), and testicular homogenate (TE). Total protein extracts of sow ovarian corpus lutea (CL) were used as the

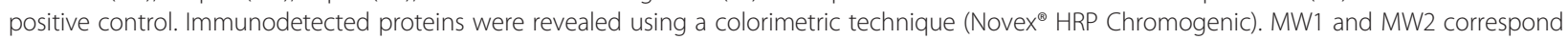
to two different molecular markers, MagicMark ${ }^{\mathrm{TM}}$ XP Western Protein Standard (1=220 kDa; $2=120$ kDa; $3=100$ kDa; $4=80$ kDa; $5=60$ kDa; $6=50 \mathrm{kDa} ; 7=40 \mathrm{kDa} ; 8=30 \mathrm{kDa} ; 9=20 \mathrm{kDa}$

accessory glands appeared immunopositive to relaxin (Figs. 5C/A-3 and 6B-E).

\section{Sperm immunofluorescence and flow cytometry evaluation}

Flow cytometry analyses revealed that the majority of spermatozoa were successfully labeled with anti-human relaxin $(80 \pm 6 \%$ to $93 \pm 1 \%)$, RXFP1 $(86 \pm 5 \%$ to $94 \pm$ $1 \%)$, and RXFP2 (79 $\pm 10 \%$ to $95 \pm 1 \%)$ antibodies. The graphical representations of antibody labeling in Fig. 7 indicate the lowest fluorescence or background signals in control groups, consisting of spermatozoa with no antibody (No-Ab) or only the secondary antibody (FITC). Fluorescence intensities of spermatozoa labeled with anti-relaxin, RXFP1, or RXFP2 antibodies were markedly greater than those of the control groups, as depicted by the right-shifted fluorescent intensity curves within the same protein target (Fig. 7). With the control groups as references, ejaculated spermatozoa consistently exhibited the narrowest fluorescence signal shifts (green arrows in Fig. 7), regardless of the protein targets (relaxin, RXFP1, and RXFP2), which coincided with their lowest mean fluorescence intensities compared to other groups (Caput, Corpus, Cauda and Vas deferens - Fig. 8: ${ }^{\text {"ast" }} \mathrm{P}<0.05$; ANOVA-1). Flow cytometry data show that corpusderived spermatozoa had significantly higher mean fluorescence intensities than any other groups, irrespective of the protein target (Fig. 8: "P $<0.05$; ANOVA-1). Within-group comparisons showed that RXFP1 mean fluorescence signals were significantly higher than those of relaxin and RXFP2, in all groups (Fig. 8: ${ }^{\mathrm{a}, \mathrm{b}},{ }^{\mathrm{c}} \mathrm{P}<0.05$; ANOVA-1), except in the caput. Both relaxin and RXFP2 signals remained comparable within each group $(\mathrm{P}>0.5$; Fig. 8$)$, and the expression patterns of both receptors mirrored relaxin detection throughout the epididymis.

\section{Immunofluorescence detection of relaxin, RXFP1, and RXFP2 in spermatozoa}

Representative images of the immunodetection of relaxin, RXFP1, and RXFP2 in epididymal and ejaculated spermatozoa are shown in Figs. 9 and 10, respectively. There was a great heterogeneity of sperm labeling with each antibody, and all targeted proteins were detected 


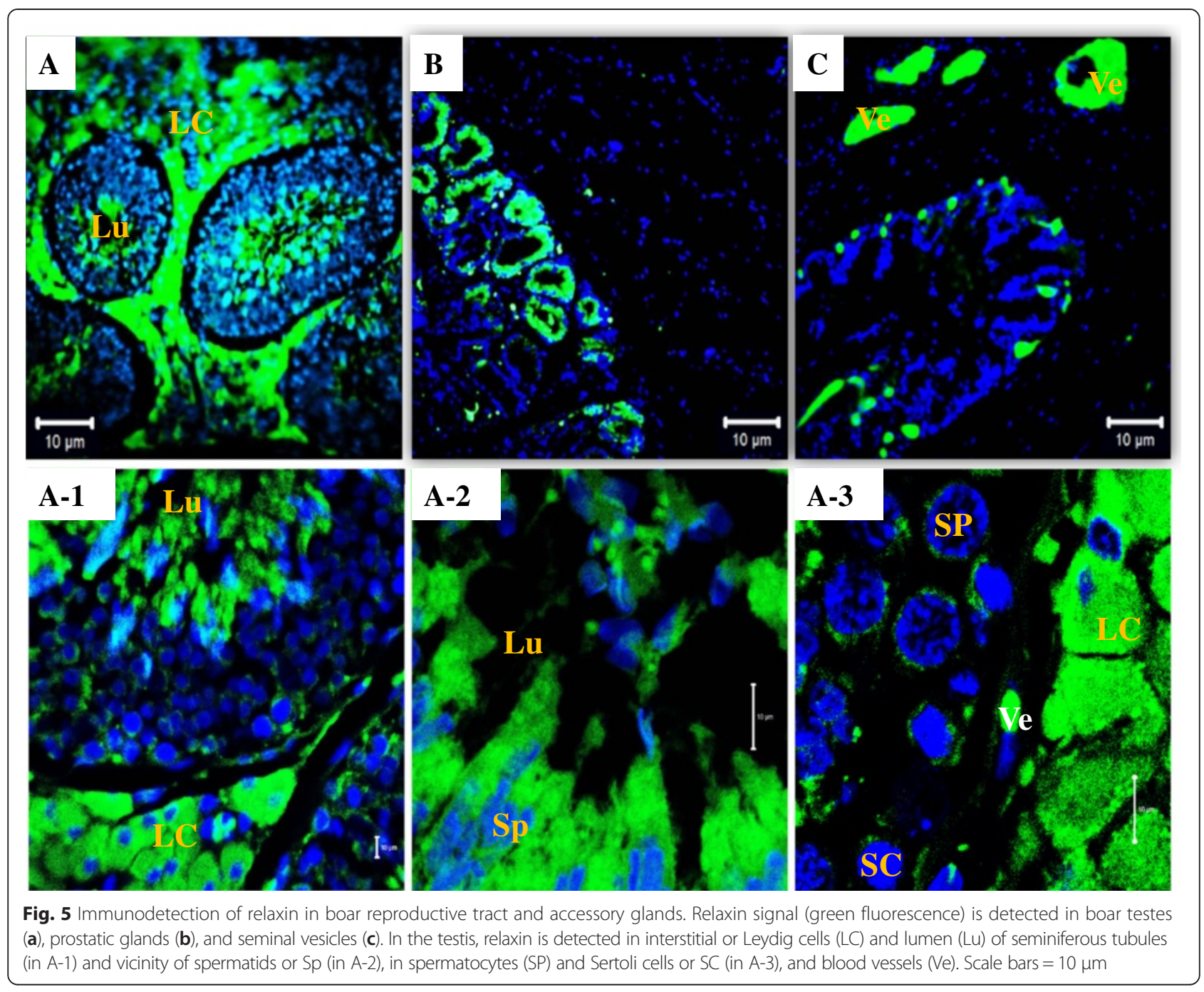

on the entire length (head, mid-piece, and tail) of both epididymal (Fig. 9) and ejaculated (Fig. 10) spermatozoa. However, the relaxin signal appeared more localized in the acrosome area and RXFP2 signals were more homogenous than RXFP1 in ejaculated sperm heads.

\section{Discussion}

Decades after its discovery [12], relaxin was and still is considered as a hormone of pregnancy and parturition despite its detection in various males species, including pigs. At present, numerous studies in rodents have brought strong evidences indicating the crucial but reversible roles of relaxin on male reproduction [33-35]. Here, we show that (i) boar reproductive tract and sex glands express relaxin receptors, (ii) boar testes rather than prostate and seminal plasma accumulate higher levels of relaxin, (iii) relaxin protein is present in the vicinity of spermatozoa upon the onset of spermatogenesis, (iv) spermatozoa possess relaxin and its receptors, suggesting autocrine and/or paracrine actions during their epididymal and post-epididymal lifespan.

\section{Validation of relaxin, RXFP1, and RXFP2 antibodies}

High levels of relaxin are detected in ovarian corpus lutea, which are known as the major source of relaxin production during pregnancy in pigs [13]. Thus, we used ovarian tissues to test the immunogenicity and specificity of a commercial rabbit antibody that targets the full length of human relaxin 1 to detect relaxin in boar tissues. This antibody has been used in previous studies to target relaxin in rat corpus luteum [36] and pig corpus luteum, germ cells, and embryos [19]. The immunofluorescence localization obtained with the commercial relaxin mirrored the rabbit anti-porcine relaxin serum signals, with various sections of the ovary stained alike. In previous studies, both antibodies successfully targeted relaxin in corpus luteum (granulosa and theca lutein) cells of various species [23, 13, 25, 37-40]. 

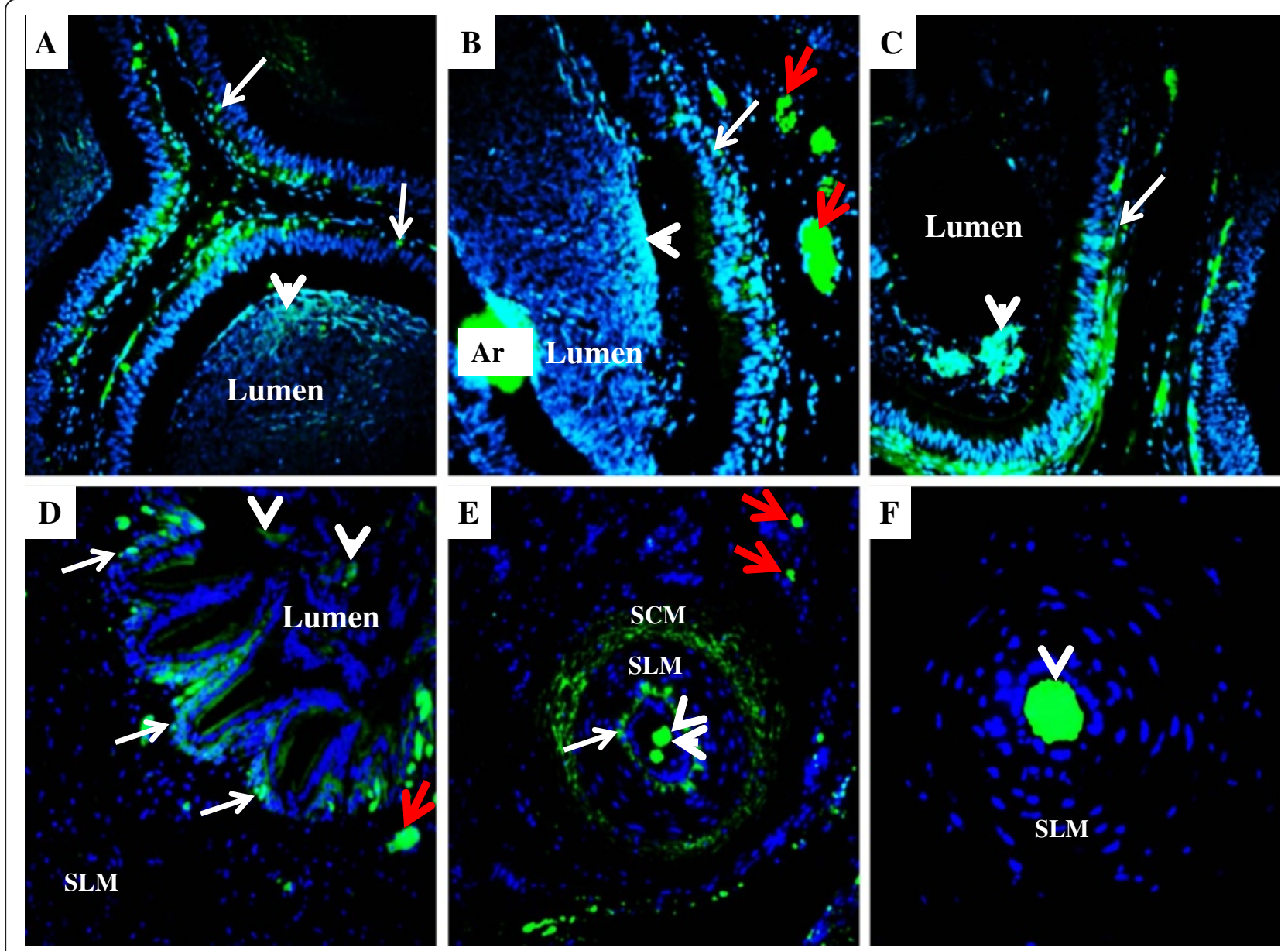

Fig. 6 Detection of relaxin in boar epididymis and vas deferens. Relaxin (green fluorescence) is detected in the epididymal caput (a), corpus (b), and cauda (c). Detection is also found in the proximal (d), middle (e), and distal (f) sections of the vas deferens. Signals are usually found in the basal cells (white arrows) and lumen of all epididymal and vas deferens sections, in the vicinity of spermatozoa (white arrow heads). Red arrows indicate relaxin signals found in the blood vessels. Nuclei are counter-stained in blue. Ar= Fluorescence artefact area; SLM = Smooth Longitudinal Muscle; SCM = Smooth Circular Muscle; 200x magnification

As to relaxin receptors, we used anti-human RXFP1 and RXFP2 antibodies because of the high degree of sequence conservations among these receptors across species. Indeed, the immunogenic sequences of each receptor have been shown to share over $99 \%$ similarity across various mammals (e.g., cattle, chimpanzee, dog, horse, human, and mice) [19]. The successful labeling of over $80 \%$ of spermatozoa in the current study further confirms the high immunogenicity of the used commercial antibodies. Moreover, the profile of bands detected with both anti-human RXFP1 and RXFP2 antibodies were similar between the male tissues and the corpus luteum, used as positive control [41]. Most importantly, the comparison of two different sources of anti-human RXFP1 antibodies (Santa Cruz vs. ACRIS antibody) showed comparable immunohistofluorescence of porcine ovary sections. The ACRIS antibody is reported to interact with porcine RXFP1 protein [42]. The current study confirms the estimated size of $82 \mathrm{kDa}$ as the mature isoform of porcine RXFP1 using the anti-human antibody from Santa Cruz Inc., Biotech, while the technical improvements (better protein resolution and appropriate molecular protein weight markers) allowed for accurate size estimations of the mature and $(90 \mathrm{kDa})$ immature (78 kDa) isoforms of RXFP2, which reverse our previous report [19] and corroborate with the commonly reported size of the mature RXFP2 isoform.

\section{Tissular immunofluorescence detection of relaxin}

The intense immunoreactivity of relaxin within the testicular interstitium (Leydig cells) was consistent with previous reports in boars employing the immunological approach [23, 43, 24]. Kato et al., used up to 10 month old pigs to detect relaxin protein signals that were restricted to the Leydig cells [24], and therefore confirmed a pioneer study that reported weaker relaxin 


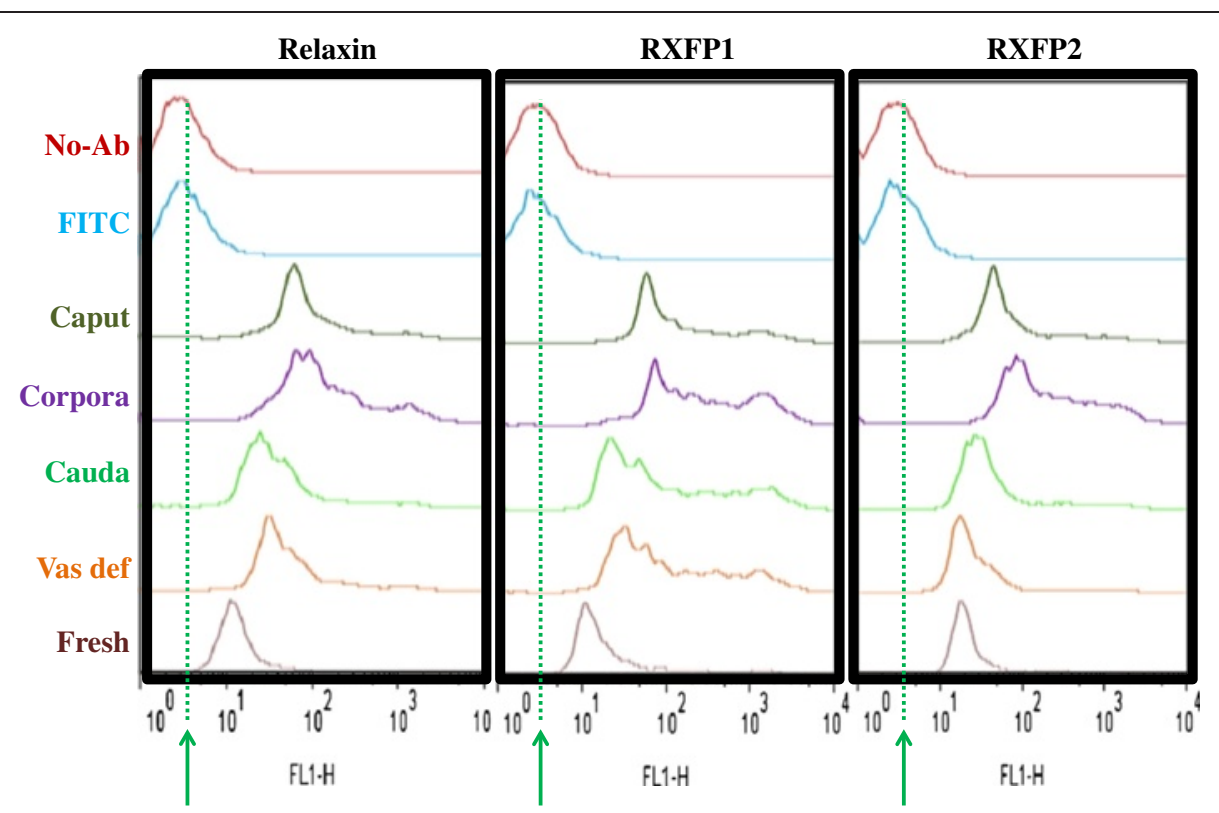

Fig. 7 Graphical representations of relaxin, RXFP1, and RXFP2. The figure represents FlowJo graphical layouts of flow cytometry analyses, following immunostaining of ejaculated (freshly collected), epididymal (caput, corpus, and cauda), and vas deferens spermatozoa. Controls corresponded to spermatozoa incubated without any (No-Ab) or only FITC-conjugated secondary (FITC) antibodies. Signal detection peaks of both controls, in each targeted protein, were comparable at the lowest levels (Green lines and arrows) in comparison to other groups

signals in boar Sertoli cells [43]. Compared to previous studies in boars $[43,24,25,23]$, we used a purified commercial antibody to confirm the presence of relaxin in various areas of the boar reproductive tract (i.e., Sertoli and seminiferous epithelial cells, spermatocytes, and lumen of seminiferous tubules and epididymis) that were still controversial in previous reports [21, 26]. Our findings provide a strong evidence of boar spermatozoa being exposed to testicular relaxin upon their release in the seminiferous lumen.

Although its main source of production in boars remains unclear [26], the combination of our findings,

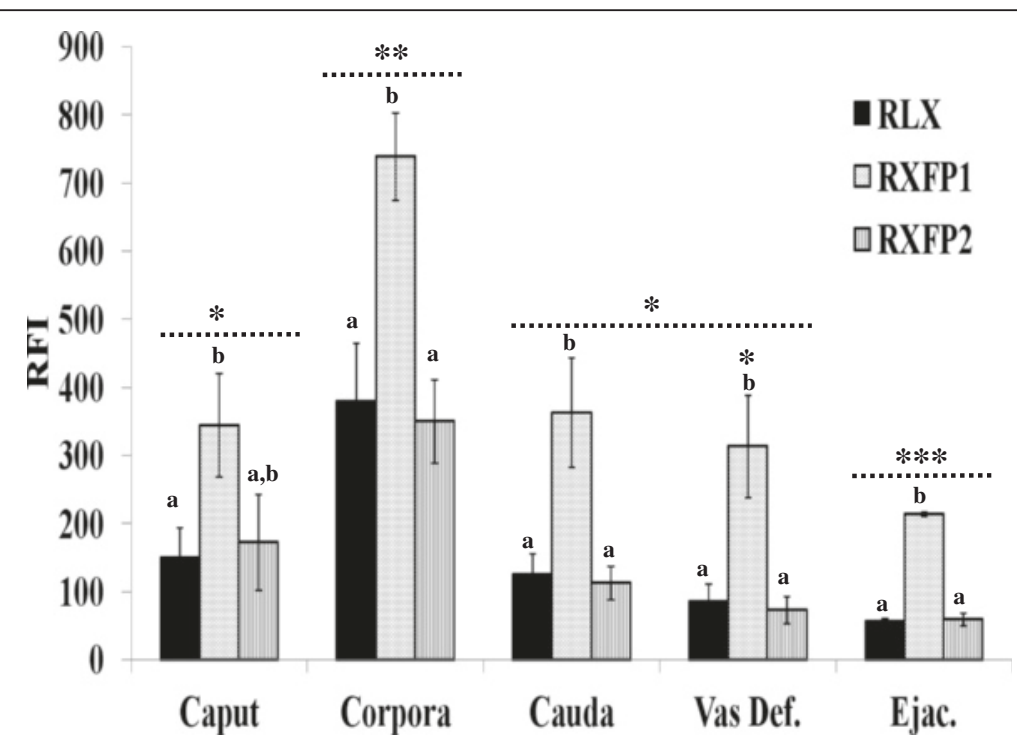

Fig. 8 Mean fluorescence detection of relaxin, RXFP1, and RXFP2 in epididymal and freshly ejaculated boar spermatozoa using flow cytometry. ,******* For each protein target (relaxin, RXFP1, and RXFP2), asterisks indicate significant differences between groups (caput, corpus, cauda, and ejaculated). Letters $(\mathbf{a}, \mathbf{b}, \mathbf{c})$ show significant differences between the protein targets within the same group (P<0.05; ANOVA-1). Data are means \pm sem of 3 boars 


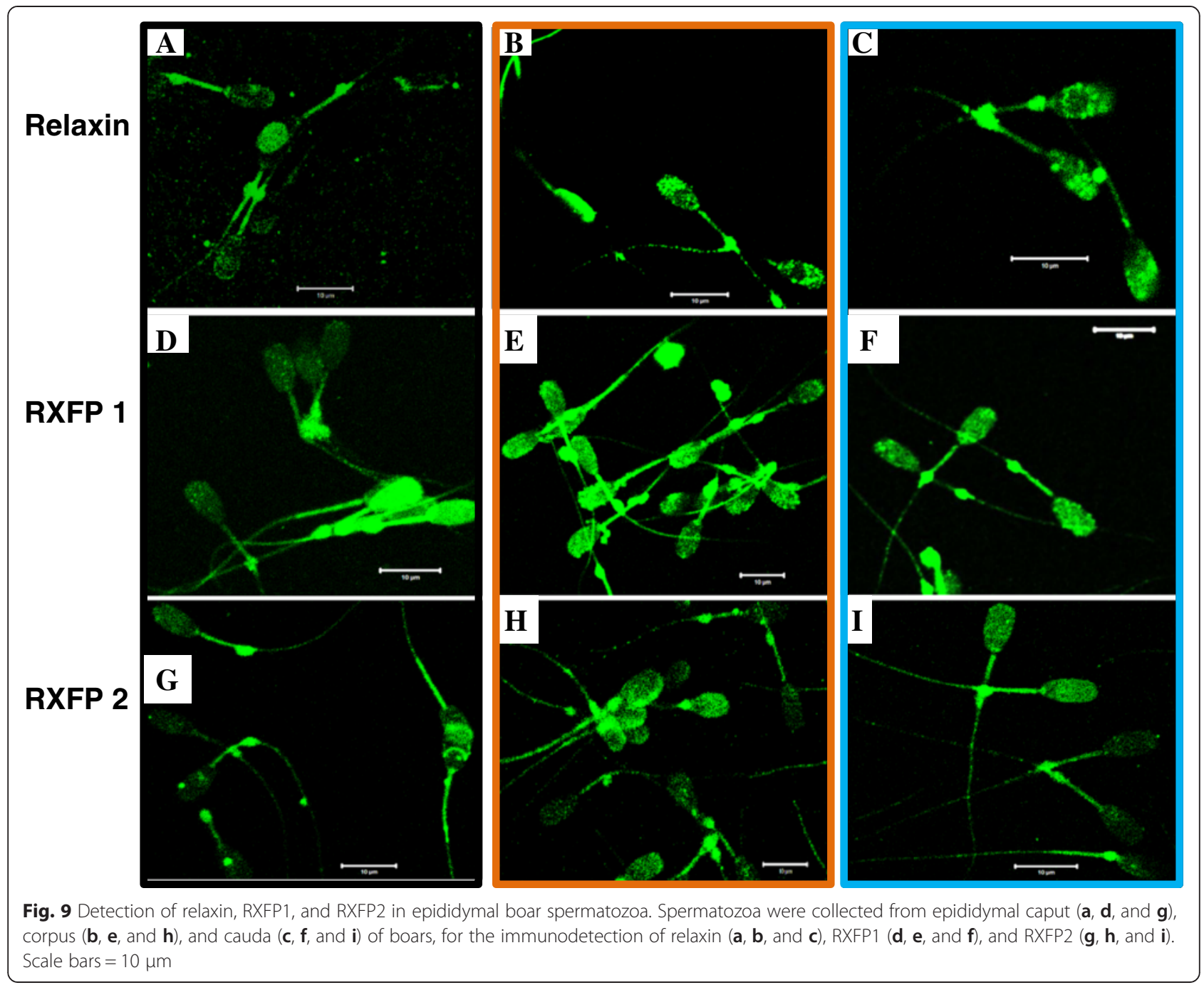

indicating differential immunofluorescence intensities of relaxin between tissues, with a recent report, showing higher expression levels of relaxin mRNA in boar testes [24] establishes strong evidences of the testes being the major production and accumulation sites of relaxin in boars. Nonetheless, the possibility of testis-produced relaxin being routed out for final processing and/or further accumulation in the prostate and seminal vesicles cannot be ruled out. A previous study has reported that boar testes mainly accumulate immature pro-pre- and pro-relaxin, due to the absence of the necessary cleavage enzyme [24], which may be an evolutionary adaptation of mammals to the lower temperature of scrotal testes. Available reports suggest a possible shift of bio-active relaxin production from abdominal testes in animals such as birds [44] and dogfish sharks [45] to sex accessory glands in mammals [21].

Furthermore, the current study indicates a greater immunodetection of relaxin in prostatic glands than that seen in seminal vesicles, which may contradict a previous suggestion that seminal vesicles produce more relaxin than prostate in boars [22], unless the larger size of the seminal vesicle is being considered for this production.

In addition, the robust immunoreactivity of relaxin within the local blood vessels is in agreement with a previous report in boars [7], and may likely be indicative of the possible back and forth vascular transportation of both immature and mature relaxin occurring between the testis and accessory glands. With the antibody used in this study targeting both immature and mature relaxin, it could then be speculated that testicular-born (immature) relaxin may gain maturity within the accessory glands [24], before being redirected via the blood vessels to direct effects during testicular growth [34], spermatogenesis [46, 24], and sperm maturation. Accessory glands are also known to dump their secretions that would also contain relaxin into the post-vas deferens duct to constitute the seminal plasma of the ejaculate and having direct effects on sperm functions (i.e., motility). 


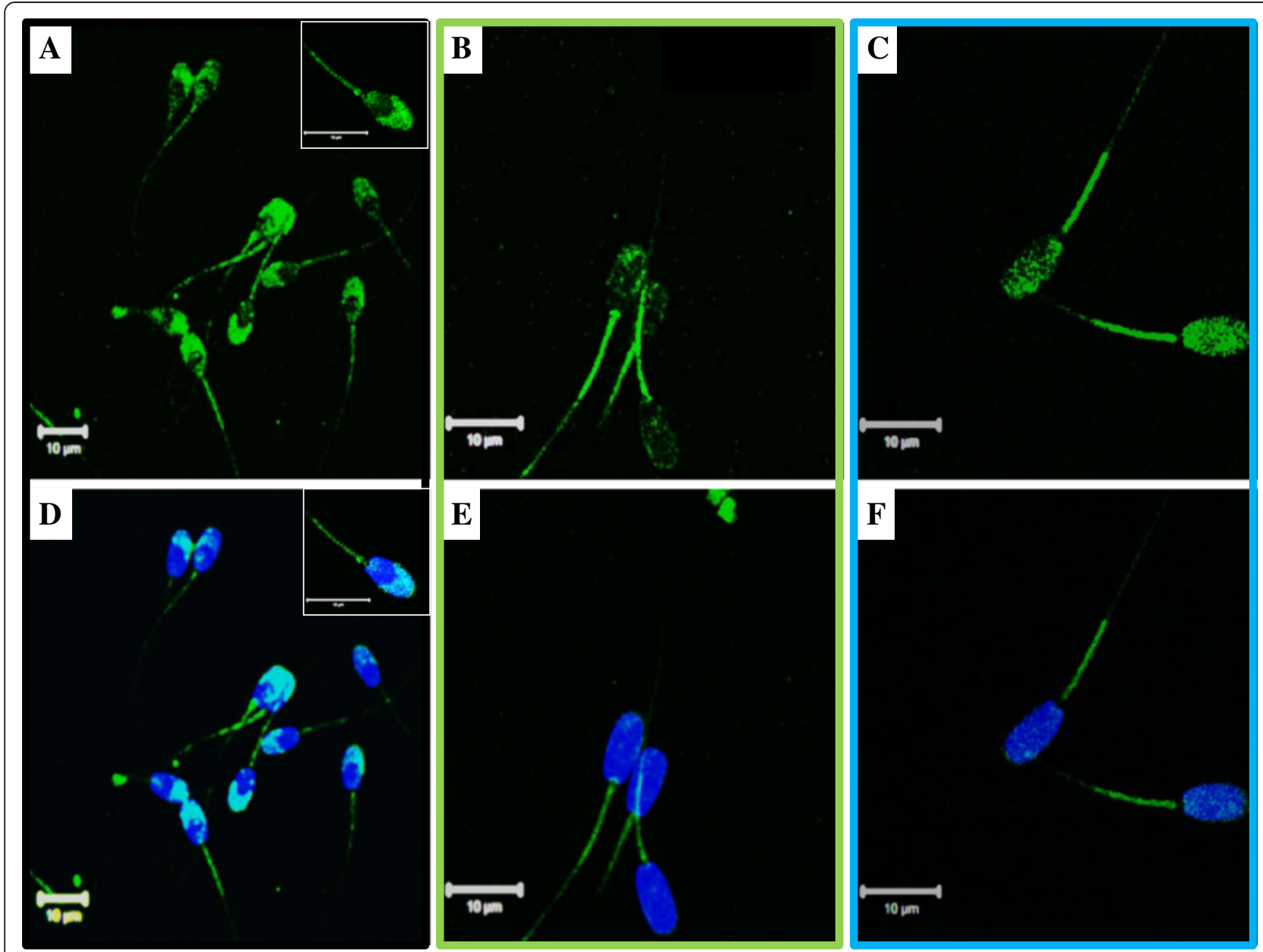

Fig. 10 Detection of relaxin, RXFP1, and RXFP2 in ejaculated boar spermatozoa. The green-FITC fluorescence indicates relaxin (a/d), RXFP1 (b/e), and RXFP2 (c/f) detection. Corresponding micrographs $\mathbf{d}, \mathbf{e}$, and $\mathbf{f}$ show the blue nuclei counterstained with DAPI. Inserts in micrographs $\mathbf{a}$ and $\mathbf{d}$ are zooms of the sperm head and mid-piece

\section{Tissular detection of relaxin receptors}

All analyzed tissues (epididymal caput, corpus, and cauda, vas deferens, prostate, and seminal vesicles) showed various RXFP1 and RXFP2 band sizes that were comparable to those found in previous studies, using porcine granulosa cells, germ cells, and corpus luteum $[19,24]$ and other in vitro models $[47,48]$. At this point, it is important to mention that RXFP2 bands were comparable although their size values were wrongly reported (78 and $62 \mathrm{kDa}$ in our previous study, instead of 90 and $78 \mathrm{kDa})$. These receptors have been detected at either or both mRNA and protein levels in male reproductive tissues of various species [21]. As suggested by previous authors $[49,50]$, the existence of multiple receptor isoforms that are likely products of RNA splicing variants may correspond to mature (82 $\mathrm{kDa}$ and $90 \mathrm{kDa}$ ) and immature $(67 \mathrm{kDa}$ and $78 \mathrm{kDa})$ isoforms of RXFP1 and $\mathrm{RXFP} 2$, respectively. Although the $32 \mathrm{kDa}$ RXFP2 band could be a truncated extracellular isoform the detected immature and mature bands appeared at slightly smaller sizes compared to their human and rat counterparts, which may be due to differential glycosylation levels between species [51, 52, 49, 50, 47]. Because these bands may correspond to isoforms synthesized for cell membrane delivery (mature), intracellular storage (immature), and extracellular excretion (truncated), the differential expression profiles of RXFP1 and RXFP2 on western immunoblotting may indicate their specific involvement in boar reproduction.

Preponderant physiological roles of relaxin-RXFP1 complexes could be speculated in testicular and epididymal cells given the higher level of immature RXFP2 and in mature spermatozoa, given the higher level of mature RXFP1 This speculation would be in agreement with previous works reporting the presence of relaxin binding sites and RXFP1 mRNA in porcine Leydig and Sertoli 
cells $[24,25]$ and expression of RXFP1 in rat Sertoli and post-meiotic germ cells [53], rhesus monkey testis [54], and human spermatozoa [29].

Unlike RXFP1, RXFP2 protein appears mainly in its immature and truncated extracellular forms in all examined tissues. This may be surprising giving the presence and roles of its major ligand, the relaxin-like factor (RFL) or insulin-like factor 3 (INSL3), on boar testes [55]. Nonetheless, the main roles of INSL3 have been described during early development [56, 57], while its protection against pro-apoptotic agents in adult animals [58] may not be preponderant in high fertile adult animals, such as the boars utilized in the current study ( 2.7 \pm 0.06 year old).

Yet, the physiological significance of the truncated extracellular isoform remains unknown and would more likely be non-functional. However, the immature isoforms of both receptors are expected to serve as pools of intracellular sequestrated receptors. This receptors' retention will allow a rapid mobilization to the plasma membrane, as needed and therefore keeping the cells at a high level of physiological responsiveness $[59,51]$. The existence of such receptor variants in boars may create unforeseeable interactions with relaxin, leading to a possible complexity of the relaxin-receptor systems that remain to be elucidated. Nonetheless, the use of knockout approaches in mice has permitted more insights into the physiological relevance of the relaxin-receptor systems, but there are still controversies in the findings according to factors such as the first generation of transgenic mice models and strains [21, 27]. Consequently, the precise and full roles of relaxin signaling during spermatogenesis and sperm maturation are still unclear. The current study shows the apparent co-detection of relaxin and its receptors in boar reproductive tissues, which indicates possible local effects of relaxin on male fertility.

\section{Immunofluorescence detection of relaxin and its receptors in spermatozoa}

Previous studies have described the presence of RXFP1 [24] and RXFP2 [55] mRNA transcripts in boar germ cells and mature spermatozoa, while the presence of relaxin transcripts in mature spermatozoa were undetected [19]. Here, we reveal the presence of corresponding proteins, as well as relaxin on both epididymal and ejaculated boar spermatozoa. The observed variations in relative expression of these proteins on spermatozoa throughout the epididymal transit can mostly be explained by the active secretory and reabsorption functions of the epididymis [60], as the transcriptional and translational machineries of spermatozoa are quasicompletely reduced.

The epididymal function is likely concomitant with the progressive decrease of sperm binding relaxin and receptors, as well as the increased sperm density to facilitate interactions between luminal fluid contents and spermatozoa achieving their epididymal maturation [1]. Therefore, the intense immunoreactivity of relaxin within the vas deferens lumen supports the possible contribution of testicular- and epididymal-born relaxin to sperm maturation and beyond. It is more likely that this luminal relaxin will later combines with prostatic and seminal vesicular relaxin in the seminal plasma, to provide further effects on sperm function via paracrine actions during its journey towards fertilization $[28,8,61]$.

Most importantly, our findings also suggest autocrine actions due to the co-localization of both relaxin and its receptors on mature spermatozoa, and thus contributing to support prolonged roles of male-born relaxin until or beyond fertilization. Indeed, beneficial effects of autocrine actions of relaxin-receptor complexes are expected on sperm motility and interactions with its surrounding within the female genital tract, as relaxin is capable of various actions that include the breakdown of tissular metalloprotein surface matrix [62], that may also affect the sperm-egg interactions and acrosome reaction of spermatozoa [29].

\section{Conclusions}

The current findings $(i)$ support the testes being the main site of relaxin production in boar, (ii) reveal that spermatozoa are exposed to relaxin upon their release into the seminiferous tubule lumen, and (iii) indicate that male-born relaxin and its RXFP1 and RXFP2 receptors found on mature spermatozoa may have important roles, via autocrine and paracrine mechanisms, on sperm motility and viability.

\section{Abbreviations}

RXFP: Relaxin family peptide receptors; ANOVA: Analysis of variances; FITC: Fluorescein isothiocyanate; FACS: Fluorescence-assisted cell sorting; PBS: Phosphate buffered solution; PVP: Polyvinylpyrrolidone.

\section{Competing interests}

The authors declare that they have no competing interests.

\section{Authors' contributions}

JMF designed the study, performed all experiments, and drafted the manuscript. JMG participated for semen collection and analyses and contributed to the manuscript. HLS-R assisted for tissue collection and preparation for immunofluorescence. JVS performed the flow cytometry analyses. MAC, STW, and PLR participated to the research design and data interpretation. All authors read and approved the final manuscript.

\section{Acknowledgements}

The authors thank Prestage Farms Inc., Mississippi Division (West-Point, MS, USA) for providing animals and collecting semen. A special thank is due to Dr. Timothy Morgan of the Department of Pathobiology and Population Medicine (College of Veterinary Medicine, Mississippi State University) for his assistance with tissues collection. We also thank Dr. Carol A. Bagnell at Rutgers University, Department of Animal Sciences, for providing the rabbit anti-porcine relaxin antibody. This work was supported by the USDA-ARS Special Initiative \# 58-6402-3-0120. 


\section{Author details}

'Department of Animal and Dairy Sciences, Facility for Organismal and Cellular Imaging (FOCI), Mississippi State University, Mississippi State, MS 39762, USA. ²Department of Pathobiology \& Population Medicine, Mississippi State University, Mississippi State, MS 39762, USA. ${ }^{3}$ Department of Basic Sciences, Flow Cytometry facility core, College of Veterinary Medicine, Mississippi State University, Mississippi State, MS 39762, USA. ${ }^{4}$ Department of Biochemistry and Molecular Biology \& Entomology and Plant Pathology, Mississippi State University, Mississippi State, MS 39762, USA. ${ }^{5}$ Department of Pathobiological Sciences, Robert P. Hanson Biomedical Sciences Laboratories, University of Wisconsin, Madison, WI 53706, USA. ${ }^{6}$ Department of Animal Science, Mayaguez Campus, University of Puerto Rico, Mayaguez, Puerto Rico.

Received: 20 November 2014 Accepted: 8 May 2015 Published online: 20 May 2015

\section{References}

1. Dacheux J-L, Dacheux F. New insights into epididymal function in relation to sperm maturation. Reproduction. 2014;147(2):R27-42.

2. Kohane AC, Gonzalez Echeverria FM, Pineiro L, Blaquier JA. Interaction of proteins of epididymal origin with spermatozoa. Biol Reprod. 1980;23(4):737-42.

3. Gatti JL, Castella S, Dacheux F, Ecroyd H, Metayer S, Thimon V, et al. Post-testicular sperm environment and fertility. Anim Reprod Sci. 2004;82-83:321-39. doi:10.1016/j.anireprosci.2004.05.011.

4. Kohane AC, Cameo MS, Pineiro L, Garberi JC, Blaquier JA. Distribution and site of production of specific proteins in the rat epididymis. Biol Reprod. 1980;23(1):181-7

5. Syntin P, Dacheux F, Druart X, Gatti JL, Okamura N, Dacheux JL. Characterization and identification of proteins secreted in the various regions of the adult boar epididymis. Biol Reprod. 1996;55(5):956-74.

6. Caballero I, Parrilla I, Almiñana C, del Olmo D, Roca J, Martínez EA, et al. Seminal Plasma Proteins as Modulators of the Sperm Function and Their Application in Sperm Biotechnologies. Reprod Domest Anim. 2012;47:12-21. doi:10.1111/j.1439-0531.2012.02028.x.

7. Juang $\mathrm{HH}$, Musah Al, Schwabe C, Ford JJ, Anderson LL. Relaxin in peripheral plasma of boars during development, copulation, after administration of hCG and after castration. J Reprod Fertil. 1996;107(1):1-6.

8. Kohsaka T, Hamano K, Sasada H, Watanabe S, Ogine T, Suzuki E. Seminal immunoreactive relaxin in domestic animals and its relationship to sperm motility as a possible index for predicting the fertilizing ability of sires. Int J Androl. 2003;26(2):115-20. doi:409.

9. Loumaye $\mathrm{E}$, De Cooman S, Thomas K. Immunoreactive relaxin-like substance in human seminal plasma. J Clin Endocrinol Metab. 1980;50(6):1142-3. doi:10.1210/jcem-50-6-1142.

10. Sasaki Y, Kohsaka T, Kawarasaki T, Sasada H, Ogine T, Bamba K. Immunoreactive relaxin in seminal plasma of fertile boars and its correlation with sperm motility characteristics determined by computer-assisted digital image analysis. Int J Andro. 2001;24(1):24-30. doi:ija259.

11. Sherwood OD. Relaxin's physiological roles and other diverse actions. Endocr Rev. 2004;25(2):205-34.

12. Hisaw F. Experimental relaxation of the pubic ligament of the guinea pig. Proc Soc Exp Biol Med. 1926;23:661-3.

13. Bagnell CA, Zhang Q, Downey B, Ainsworth L. Sources and biological actions of relaxin in pigs. J Reprod Fertil Suppl. 1993;48:127-38.

14. Einspanier A, Zarreh-Hoshyari-Khah M, Balvers M, Kerr L, Fuhrmann K, Ivell R. Local relaxin biosynthesis in the ovary and uterus through the oestrous cycle and early pregnancy in the female marmoset monkey (Callithrix jacchus). Hum Reprod. 1997;12(6):1325-37. doi:10.1093/humrep/12.6.1325.

15. Sanborn BM, Kuo HS, Weisbrodt NW, Sherwood OD. The interaction of relaxin with the rat uterus. I. Effect on cyclic nucleotide levels and spontaneous contractile activity. Endocrinology. 1980;106(4):1210-5. doi:10.1210/endo-106-4-1210

16. Hsu SY, Nakabayashi K, Nishi S, Kumagai J, Kudo M, Sherwood OD, et al. Activation of orphan receptors by the hormone relaxin. Science. 2002;295(5555):671-4. doi:10.1126/science.1065654.

17. Dschietzig T, Bartsch C, Baumann G, Stangl K. Relaxin-a pleiotropic hormone and its emerging role for experimental and clinical therapeutics. Pharmacol Ther. 2006;112(1):38-56. doi:10.1016/j.pharmthera.2006.03.004. S0163-7258(06)00041-6.
18. Stewart DR, Overstreet JW, Celniker AC, Hess DL, Cragun JR, Boyers SP, et al. The relationship between $\mathrm{hCG}$ and relaxin secretion in normal pregnancies vs peri-implantation spontaneous abortions. Clin Endocrinol (Oxf). 1993:38(4):379-85.

19. Feugang JM, Rodriguez-Munoz JC, Willard ST, Bathgate RA, Ryan PL. Examination of relaxin and its receptors expression in pig gametes and embryos. Reprod Biol Endocrinol. 2011;9:10. doi:10.1186/1477-7827-9-10 1477-7827-9-10.

20. Gunnersen JM, Crawford RJ, Tregear GW. Expression of the relaxin gene in rat tissues. Mol Cell Endocrinol. 1995;110(1-2):55-64.

21. Ivell R, Kotula-Balak M, Glynn D, Heng K, Anand-Ivell R. Relaxin family peptides in the male reproductive system-a critical appraisal. Mol Hum Reprod. 2011;17(2):71-84. doi:10.1093/molehr/gaq086.

22. Kohsaka T, Takahara H, Sasada H, Kawarasaki T, Bamba K, Masaki J, et al. Evidence for immunoreactive relaxin in boar seminal vesicles using combined light and electron microscope immunocytochemistry. J Reprod Fertil. 1992;95(2):397-408.

23. Arakaki RF, Kleinfeld RG, Bryant-Greenwood GD. Immunofluorescence studies using antisera to crude and to purified porcine relaxin. Biol Reprod. 1980;23(1):153-9.

24. Kato S, Siqin, Minagawa I, Aoshima T, Sagata D, Konishi H. Evidence for expression of relaxin hormone-receptor system in the boar testis. J Endocrinol. 2010;207(2):135-49. doi:10.1677/JOE-10-0149.

25. Min G, Sherwood OD. Localization of specific relaxin-binding cells in the ovary and testis of pigs. Biol Reprod. 1998;59(2):401-8.

26. Weiss G. Relaxin in the male. Biol Reprod. 1989;40(2):197-200.

27. Nascimento AR, Pimenta MT, Lucas TF, Royer C, Porto CS, Lazari MF. Intracellular signaling pathways involved in the relaxin-induced proliferation of rat Sertoli cells. Eur J Pharmacol. 2012;691(1-3):283-91. doi:10.1016/ j.ejphar.2012.07.021 S0014-2999(12)00614-0.

28. Brenner SH, Lessing JB, Schoenfeld C, Amelar RD, Dubin L, Weiss G. Stimulation of human sperm cervical mucus penetration in vitro by relaxin. Fertil Steril. 1984;42(1):92-6.

29. Ferlin A, Menegazzo M, Gianesello L, Selice R, Foresta C. Effect of relaxin on human sperm functions. J Androl. 2012:33(3):474-82. doi:10.2164/ jandrol.110.012625

30. Miah AG, Tareq KM, Hamano K, Kohsaka T, Tsujii H. Effect of relaxin on acrosome reaction and utilization of glucose in boar spermatozoa. J Reprod Dev. 2006;52(6):773-9. doi: JST. JSTAGE/jrd/18037.

31. Feugang JM, Greene JM, Willard ST, Ryan PL. In vitro effects of relaxin on gene expression in porcine cumulus-oocyte complexes and developing embryos. Reprod Biol Endocrinol. 2011;9:15. doi:10.1186/ 1477-7827-9-15.

32. Feugang JM, Youngblood RC, Greene JM, Fahad AS, Monroe WA, Willard ST. Application of quantum dot nanoparticles for potential non-invasive bio-imaging of mammalian spermatozoa. J Nanobiotechnology. 2012;10:45. doi:10.1186/1477-3155-10-45

33. Krajnc-Franken MA, van Disseldorp AJ, Koenders JE, Mosselman S, van Duin M, Gossen JA. Impaired nipple development and parturition in LGR7 knockout mice. Mol Cell Biol. 2004;24(2):687-96.

34. Samuel CS, Tian H, Zhao L, Amento EP. Relaxin Is a Key Mediator of Prostate Growth and Male Reproductive Tract Development. Lab Invest. 2003;83(7):1055-67.

35. Samuel CS, Lin F, Hossain MA, Zhao C, Ferraro T, Bathgate RA, et al. Improved chemical synthesis and demonstration of the relaxin receptor binding affinity and biological activity of mouse relaxin. Biochemistry. 2007;46(18):5374-81. doi:10.1021/bi700238h.

36. Benoit AM, LaVoie HA, McCoy GL, Blake CA. Expression of sperm protein 22 (SP22) in the rat ovary during different reproductive states. Exp Biol Med (Maywood). 2007;232(7):910-20. doi:232/7/910.

37. Bagnell CA, Baker NK, McMurtry JP, Brocht DM, Lewis GS. Control of luteal relaxin release by prostaglandin $\mathrm{F} 2$ alpha: differences in the sow cycle and pregnancy. Proc Soc Exp Biol Med. 1990;194(2):125-30.

38. Fields PA, Lee AB, Haab LM, Hwang JJ, Sherwood OD. Evidence for a dual source of relaxin in the pregnant rat: immunolocalization in the corpora lutea and endometrium. Endocrinology. 1992;130(5):2985-90.

39. Kohsaka T, Singh U, Yogo K, Sasada H, Taya K, Hashizume K. Expression and cellular pattern of relaxin mRNA in porcine corpora lutea during pregnancy. Cell Tissue Res. 2007:330(2):303-12.

40. Yki-Jarvinen H, Wahlstrom T, Seppala M. Immunohistochemical Demonstration of Relaxin in the Genital Tract of Pregnant and Nonpregnant Women. J Clin Endocrinol Metab. 1983;57(3):451-4. doi:10.1210/jcem-57-3-451. 
41. Ali SM, McMurtry JP, Bagnell CA, Bryant-Greenwood GD. Immunocytochemical localization of relaxin in corpora lutea of sows throughout the estrous cycle. Biol Reprod. 1986;34(1):139-43.

42. Yan W, Wiley AA, Bathgate RA, Frankshun AL, Lasano S, Crean BD. Expression of LGR7 and LGR8 by neonatal porcine uterine tissues and transmission of milk-borne relaxin into the neonatal circulation by suckling. Endocrinology. 2006;147(9):4303-10. doi:10.1210/en.2006-0397.

43. Dubois MP, Dacheux JL. Relaxin, a male hormone? Immunocytological localization of a related antigen in the boar testis. Cell Tissue Res. 1978;187(2):201-14.

44. Steinetz BG, Beach VL, Tripp LV, Defalco RJ. Reactions of Antisera to Porcine Relaxin with Relaxin-Containing Tissues of Other Species in Vivo and in Vitro. Acta Endocrinol (Copenh). 1964;47:371-84.

45. Steinetz BG, Schwabe C, Callard IP, Goldsmith LT. Dogfish shark (Squalus acanthias) testes contain a relaxin. J Androl. 1998;19(1):110-5.

46. Cardoso LC, Nascimento AR, Royer C, Porto CS, Lazari MFM. Locally produced relaxin may affect testis and vas deferens function in rats. Reproduction. 2010;139(1):185-96. doi:10.1530/rep-09-0146.

47. Kern A, Bryant-Greenwood GD. Characterization of relaxin receptor (RXFP1) desensitization and internalization in primary human decidual cells and RXFP1-transfected HEK293 cells. Endocrinology. 2009;150(5):2419-28. doi:10.1210/en.2008-1385.

48. Kumagai J, Hsu SY, Matsumi H, Roh JS, Fu P, Wade JD, et al. INSL3/Leydig insulin-like peptide activates the LGR8 receptor important in testis descent. J Biol Chem. 2002;277(35):31283-6. doi:10.1074/jbc.C200398200.

49. Muda M, He C, Martini PGV, Ferraro T, Layfield S, Taylor D, et al. Splice variants of the relaxin and INSL3 receptors reveal unanticipated molecular complexity. Mol Hum Reprod. 2005;11(8):591-600. doi:10.1093/molehr/gah205.

50. Scott DJ, Layfield S, Yan Y, Sudo S, Hsueh AJ, Tregear GW. Characterization of novel splice variants of $L G R 7$ and $L G R 8$ reveals that receptor signaling is mediated by their unique low density lipoprotein class A modules. J Biol Chem. 2006;281(46):34942-54. doi:10.1074/jbc.M602728200.

51. Kern A, Agoulnik Al, Bryant-Greenwood GD. The low-density lipoprotein class A module of the relaxin receptor (leucine-rich repeat containing G-protein coupled receptor 7): its role in signaling and trafficking to the cell membrane. Endocrinology. 2007;148(3):1181-94. doi:10.1210/en.2006-1086.

52. Kern A, Hubbard D, Amano A, Bryant-Greenwood GD. Cloning, expression, and functional characterization of relaxin receptor (leucine-rich repeat-containing g protein-coupled receptor 7) splice variants from human fetal membranes. Endocrinology. 2008;149(3):1277-94. doi:10.1210/en.2007-1348.

53. Filonzi M, Cardoso LC, Pimenta MT, Queiroz DB, Avellar MC, Porto CS. Relaxin family peptide receptors Rxfp1 and Rxfp2: mapping of the mRNA and protein distribution in the reproductive tract of the male rat. Reprod Biol Endocrinol. 2007;5:29. doi:10.1186/1477-7827-5-29.

54. Silvertown JD, Neschadim A, Liu HN, Shannon P, Walia JS, Kao JC. Relaxin-3 and receptors in the human and rhesus brain and reproductive tissues. Regul Pept. 2010;159(1-3):44-53. doi:10.1016/j.regpep.2009.09.007 S01670115(09)00201-8

55. Minagawa I, Sagata D, Pitia AM, Kohriki H, Shibata M, Sasada H. Dynamics of insulin-like factor 3 and its receptor expression in boar testes. J Endocrinol. 2014;220(3):247-61. doi:10.1530/JOE-13-0430.

56. Gorlov IP, Kamat A, Bogatcheva NV, Jones E, Lamb DJ, Truong A, et al. Mutations of the GREAT gene cause cryptorchidism. Hum Mol Genet. 2002;11(19):2309-18.

57. Overbeek PA, Gorlov IP, Sutherland RW, Houston JB, Harrison WR, Boettger-Tong HL. A transgenic insertion causing cryptorchidism in mice. Genesis. 2001;30(1):26-35. doi:10.1002/gene.1029.

58. Kawamura K, Kumagai J, Sudo S, Chun SY, Pisarska M, Morita H, et al. Paracrine regulation of mammalian oocyte maturation and male germ cell survival. Proc Natl Acad Sci U S A. 2004;101(19):7323-8. doi:10.1073/ pnas.0307061101.

59. Achour L, Labbe-Jullie C, Scott MG, Marullo S. An escort for GPCRs: implications for regulation of receptor density at the cell surface. Trends Pharmacol Sci. 2008;29(10):528-35. doi:10.1016/ j.tips.2008.07.009. S0165-6147(08)00169-7.

60. Dacheux J-L, Gatti JL, Dacheux F. Contribution of epididymal secretory proteins for spermatozoa maturation. Microsc Res Tech. 2003;61(1):7-17.
61. Robertson SA. Seminal fluid signaling in the female reproductive tract: lessons from rodents and pigs. J Anim Sci. 2007;85(13):E36-44. doi:10.2527/ jas.2006-578.

62. Bathgate RAD, Halls ML, van der Westhuizen ET, Callander GE, Kocan M, Summers RJ. Relaxin Family Peptides and Their Receptors. Physiol Rev. 2013;93(1):405-80. doi:10.1152/physrev.00001.2012.

\section{Submit your next manuscript to BioMed Central and take full advantage of:}

- Convenient online submission

- Thorough peer review

- No space constraints or color figure charges

- Immediate publication on acceptance

- Inclusion in PubMed, CAS, Scopus and Google Scholar

- Research which is freely available for redistribution 